\title{
Serum Biomarkers for Early Detection of Hepatocellular Carcinoma Associated with HCV Infection in Egyptian Patients
}

\author{
Abdel-Rahman Zekri ${ }^{1 *}$, Amira Salah El-Din Youssef ${ }^{1}$, Yasser Mabrouk Bakr ${ }^{1}$, \\ Reham Mohamed Gabr ${ }^{1}$, Mahmoud Nour El-Din El-Rouby ${ }^{1}$, Ibtisam Hammad ${ }^{2}$, \\ Entsar Abd El-Monaem Ahmed ${ }^{2}$, Hanan Abd El-Haleem Marzouk ${ }^{3}$, Mohammed \\ Mahmoud Nabil ${ }^{3}$, Hanan Abd El-Hafez Hamed ${ }^{3}$, Yasser Hamada Ahmed \\ Aly ${ }^{3}$ Khaled S Zachariah ${ }^{3}$, Gamal Esmat ${ }^{3}$
}

\begin{abstract}
Background: Early detection of hepatocellular carcinoma using serological markers with better sensitivity and specificity than alpha fetoprotein (AFP) is needed. Aims: The aim of this study was to evaluate the diagnostic value of serum sICAM-1, $\beta$-catenin, IL-8, proteasome and STNFR-II in early detection of HCC. Materials and Methods: Serum levels of IL-8, sICAM-1, sTNFR-II, proteasome and $\beta$-catenin were measured by ELISA assay in 479 serum samples from 192 patients with HCC,96 patients with liver cirrhosis (LC), 96 patients with chronic hepatitis $\mathrm{C}$ (CHC) and 95 healthy controls. Results: Serum levels of proteasome, sICAM-1, $\beta$-catenin and $\alpha$ FP were significantly elevated in HCC group compared to other groups (P-value $<0.001)$, where serum level of IL-8 was significantly elevated in the $\mathrm{LC}$ and $\mathrm{HCC}$ groups compared to $\mathrm{CHC}$ and control groups (P-value $<0.001)$, while no significant difference was noticed in patients with HCC and LC (P-value=0.09). Serum level of sTNFRII was significantly elevated in patients with LC compared to $\mathrm{HCC}, \mathrm{CHC}$ and control groups (P-value $<0.001)$; also it was significantly higher in HCC compared to $\mathrm{CHC}$ and control groups (P-value $<0.001)$. ROC curve analysis of the studied markers between HCC and other groups revealed that the serum level of proteasome had sensitivity of $75.9 \%$ and specificity of $73.4 \%$ at a cut-off value of $0.32 \mu \mathrm{g} / \mathrm{ml}$ with AUC $0.803 \mathrm{sICAM}-1$ at cut off value of $778 \mathrm{ng} / \mathrm{ml}$, the sensitivity was $75.8 \%$ and the specificity was $71.8 \%$ with AUC 0.776 . $\beta$-catenin had sensitivity and specificity of $70 \%$ and $68.6 \%$ respectively at a cut off value of $8.75 \mathrm{ng} / \mathrm{ml}$ with an AUC of 0.729 . STNFR-II showed sensitivity of $86.3 \%$ and specificity of $51.8 \%$ at a cut off value of $6239.5 \mathrm{pg} / \mathrm{ml}$ with an AUC of 0.722 . IL-8 had sensitivity of $70.4 \%$ and specificity of $52.3 \%$ at a cut off value of $51.5 \mathrm{pg} / \mathrm{ml}$ with AUC 0.631 . Conclusions: Our data supported the role of proteasome, sICAM-1, sTNFR-II and $\beta$-catenin in early detection of HCC. Also, using this panel of serological markers in combination with $\alpha$ FP may offer improved diagnostic performance over $\alpha \mathrm{FP}$ alone in the early detection of HCC.
\end{abstract}

Keywords: Hepatocellular carcinoma - $\alpha$ FP - sICAM-1 - proteasome - $\beta$-catenin - IL-8 - sTNFR-II

Asian Pac J Cancer Prev, 16 (3), 1281-1287

\section{Introduction}

Hepatocellular carcinoma (HCC) is one of the most common primary malignancies of the liver which is not only increasing the global incidence but also is a major cause of cancer related mortality especially with a male predominance (Hiotis et al., 2012; Etsuji, 2013). Among the risk factors for developing $\mathrm{HCC}$ is the emergence of the hepatitis $\mathrm{C}$ virus (HCV), as it is considered to be the second most common cause of HCC and the leading etiology in Egypt, Japan and within the USA (Yamashita et al., 2011). Egypt has the highest prevalence of HCV in the world, estimated among the general population to be around 14\% (El-Zanaty et al., 2009).
The long term survival of postoperative HCC patients is unsatisfactory for the high incidence of recurrence. Moreover, HCC detection by serum $\alpha$ FP level is limited by its low sensitivity, so there is an urgent demand to identify new serological markers with high accuracy and feasibility for the early detection of HCC (Zhou et al., 2013). Serological markers could be divided into proteantigens, cytokines, enzymes and isoenzymes as well as transcripts of related genes (Zhou et al., 2013). In the current study, we aim to focus on the role of Interleukin 8 (IL8), soluble intercellular adhesion molecule -1 (sICAM-1), $\mathrm{b}$ etacatenin ( $\beta$-catenin), soluble tumor necrosis factor receptor II (sTNFR-II) and proteasome as serological markers in the early detection of HCC.

\footnotetext{
${ }^{1}$ Virology and Immunolgy Unit, Cancer Biology Department, National Cancer Institute, ${ }^{3}$ Department of Endemic Medicine and Hepatology, Faculty of Medicine, Cairo University, ${ }^{2}$ Botany and Microbiology Department, Faculty of Science, Helwan University, Cairo, Egypt*For correspondence: ncizekri@yahoo.com
} 
ICAM-1 is a proteantigen cell surface glycoprotein of the immunoglobulin super family. The expression of ICAM-1 mediates adhesion-dependent cell-cell interactions and facilitates the movement (or retention) of cells through the extracellular matrix which plays an important role in cells differentiation, movement and immunity (Lawson et al., 2009). In malignances the expression of ICAM-1 is up regulated due to its secretion by tumor cells, which may be one mechanism of tumor cells evading the body's immunity (Bernier et al., 2011). Therefore, it is of interest to elucidate the role of serum sICAM-1as a serological tumor marker in HCC patients.

Beta-catenin (proteantigen) is as a protein associated with the intracellular domain of E-cadherin, a component of the adherents junction (Aberle et al., 1996) . $\beta$-catenin is an essential component of the Wnt/Wingless ( $\mathrm{Wg}$ ) signaling pathway which is involved in a large variety of developmental processes, including cell fate regulation, proliferation and self-renewal of stem and progenitor cells (Clevers, 2006). Mutation affecting Wnt/ $\beta$-catenin pathway appears to be the most frequent event in HCC, and have been found in 20-40\% of these tumors (LaurentPuig et al., 2006). Therefore, it is of interest to illustrate the role of serum $\beta$-catenin in early detection of HCC.

The Proteasome is the main non-lysosomal proteolytic enzyme complex responsible for degrading proteins tagged by the ubiquitin conjugation system. It plays a vital role in degradation of short half-life proteins and peptides that are involved in basic cellular processes, such as cell-cycle regulation and apoptosis, transcriptional regulation, or antigen processing (Sorokin et al., 2009). The Proteasome most exclusively used in mammals is the cytosolic 26S Proteasome, which containing one 20S protein subunit and two 19S regulatory cap subunits (Sorokin et al., 2009). It has been reported that Proteasomes are often overexpressed in cancer e.g Human leukemia (Kumatori et al., 1990), renal cancer (Kanayama et al., 1991) and hepatocellular carcinoma (Henry et al., 2009). Therefore, it is of interest to elucidate the role of serum Proteasome as prognostic marker in early detection of HCC.

Interleukin-8 (IL-8), alternatively known as CXCL8, is a pro inflammatory $\mathrm{CXC}$ chemokine associated with the promotion of neutrophil chemotaxis (Waugh et al., 2008). IL-8 is produced by a wide variety of cell types, including macrophages, neutrophils, fibroblasts, and endothelial cells (Adler et al., 1994). It has direct effects on tumor and vascular endothelial cell proliferation, angiogenesis, and tumor migration (McConnell et al., 2009). Recent researches have indicated that IL-8 regulates tumor cell growth and metastasis in liver (Ren et al., 2003). Therefore, it is of interest to elucidate the role of serum IL-8 as a biological tumor marker in HCC patients.

Tumor necrosis factor-alpha $(\mathrm{TNF}-\alpha)$ is a proinflammatory cytokine with a major role in both acute and chronic responses to viral, bacterial, fungal and parasitic infections (Bradley, 2008). TNF mediates various cellular responses by binding to two structurally distinct receptors: TNF receptor-1 (TNFR-I) and TNF receptorII (TNFR-II), members of the TNFR superfamily (Rothe et al., 1992). Soluble TNF alpha receptors (sTNFR- I and II) are useful tools to investigate TNF alpha release, which itself has a short half-life (Diez-Ruiz et al., 1995). It was previously reported that serum level of sTNFR-II was upregulated in hepatocellular carcinoma (Zekri et al., 2010). Therefore, it is of interest to elucidate the role of serum IL-8 as a biological tumor marker in HCC patients.

This current study was conducted as a confirmatory study of our previously published data by (Zekri et al., 2009), (Zekri et al., 2010) and (Zekri et al., 2011) in order to address the potential role of SICAM-1, $\beta$-catenin, Proteasome, IL-8 and sTNFR-II in early detection of HCC.

\section{Materials and Methods}

\section{Study design}

It was a case-control study conducted on 384 adult patients with HCV related chronic diseases divided into three groups: group $1(\mathrm{HCC} ; \mathrm{n}=192)$ attending the multidisciplinary HCC clinic, Tropical Medicine Department, Faculty of Medicine and National cancer institute (NCI), Cairo University; group 2 (Cirrhotic; n=96) attending Endemic Medicine Department ,Faculty of Medicine, Cairo University and group 3 (CHC; n=96) who were recruited from Kasr El Aini Viral Hepatitis Center, Faculty of Medicine, Cairo University, in addition to 95 healthy subjects who were enrolled as the control group during the period from May 2012 to April 2013. The study was approved by the Investigation and Ethics Committee of the hospital and a written consent was obtained from all the persons involved.

The HCC group was diagnosed by abdominal ultrasonography, triphasic CT abdomen, serum $\alpha \mathrm{FP}$ and confirmed histopathologically with no evidence of local invasion or distant metastasis; Cirrhotic group was diagnosed by abdominal ultrasonography and patients with CHC group with elevated ALT for more than six months. The control group had no clinical or biochemical evidence of liver disease or known medical illness at recruitment and with normal abdominal ultra-sonography. All controls were negative for $\mathrm{HBV}$ and $\mathrm{HCV}$ infection as evidenced by negative serological markers and negative PCR for $\mathrm{HBV}$ and $\mathrm{HCV}$. Exclusion criteria were patients with $\mathrm{HBV}$ infection and patients with $\mathrm{HCC}$ who received previous treatment or antiviral therapy for HCV. A detailed history, clinical assessment, biochemical liver profile, abdominal ultrasonography were done to all study groups in addition to serological testing and abdominal ultrasonography with Doppler examination to identify focal lesions and Triphasic CT scan for patients with hepatic focal lesions.

Collection of clinical specimens: $5 \mathrm{ml}$ of venous blood was left to coagulate, and then centrifuged at 5000 rpm for 10 minutes. Serum was collected after a second centrifugation and then stored at $-800 \mathrm{C}$ until used.

\section{Measurement of serum biomarkers}

Serum levels of, sICAM-1, IL-8, sTNFR-II were measured by a commercially available ELISA kit from (R\&D Systems, Inc., USA), Proteasome was measured by ELISA kit from (Enzo Life Sciences, Inc., Switzerland ) and $\beta$-catenin was measured by ELISA kit from (Glory Science Co., Ltd, USA) according to the manufacturer's instructions. 
Serum Biomarkers for Early Detection of Hepatocellular Carcinoma Associated with HCV Infection in Egyptian Patients

Statistical analysis

The SPSS software package (version 15) was used. Continuous variables were expressed as mean $\pm \mathrm{SD}$, median and interquartile range. Comparisons between groups were analyzed by the $\chi 2$ test or Fisher's exact test for categorical variables, and by the Mann-Whitney test or Student's t-test when appropriate for continous variables. P-value was considered significant when P-value $\leq 0.05$. Correlation between the variables is calculated using Pearson's product moment correlation coefficient. Receiver operating characteristic (ROC) curves are plotted in order to determine the best cut-off values of the studied markers with its sensitivity and specificity.

\section{Results}

Detailed clinical data of all studied groups are shown in Table (1). Smokers were significantly higher in HCC compared to other groups (P-value $<0.001)$. The median value of $\alpha \mathrm{FP}$ was significantly higher in HCC compared to other groups ( $\mathrm{P}$-value $<0.001)$. The percentage of diabetic patients was significantly higher in HCC and LC groups compared to $\mathrm{CHC}$ and control groups (P-value $<0.001$ ). The percentage of ascites in LC group was significantly higher compared to other groups (P-value $<0.001)$. The median value of AST was significantly higher in HCC group compared to other groups. The median value of albumin was significantly higher in normal group than the other studied groups (P-value<0.001). The median of Tbilirubin was significantly higher in LC group compared to other groups (P-value $<0.001)$. The median value of ALT was significantly higher in $\mathrm{HCC}, \mathrm{LC}$ and $\mathrm{CHC}$ groups compared to normal controls (P-value <0.001). Also it was noticed that there were a trend of elder age with progression of liver disease from $\mathrm{CHC}$ through cirrhosis to $\mathrm{HCC}$ groups, as the mean value of age for $\mathrm{HCC}$ was significantly different from $\mathrm{LC}, \mathrm{CHC}$ and control group also mean value of age for $\mathrm{CHC}$ group was significantly different from control group ( $\mathrm{P}$-value $<0.001)$. The severity of liver disease in the HCC and cirrhotic groups was

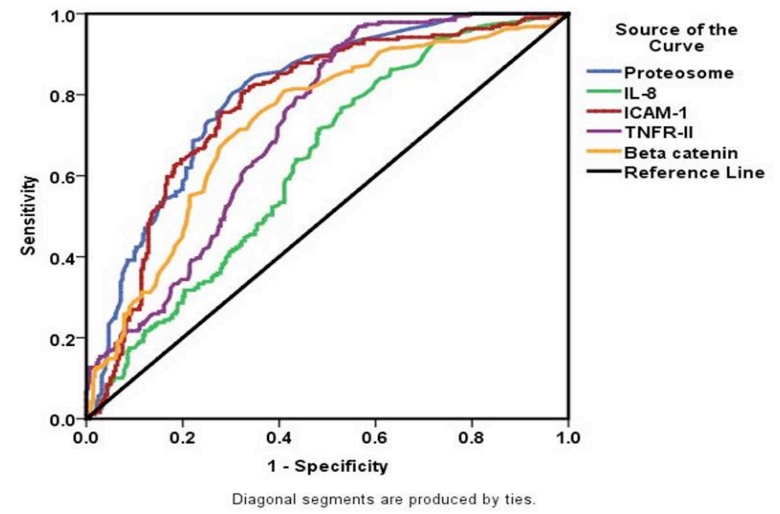

Figure 1. ROC Curve Analysis for Different Studied Markers between HCC (Malignant Cases) and Other Studied Groups (Non-Malignant Cases)

Table 1. Clinical Data of the Studied Groups

\begin{tabular}{|c|c|c|c|c|c|c|}
\hline & & No & $\mathrm{HCC} \mathrm{n=192}$ & Cirrhotic $n=96$ & Non-Cirrhotic n=96 & Control $n=95$ \\
\hline \multicolumn{2}{|c|}{ Age: mean \pm SD (Range) } & & $\begin{array}{c}56.7 \pm 7.7 \mathrm{a} \\
(29-80)\end{array}$ & $\begin{array}{c}54.01 \pm 8.3 b \\
(27-66)\end{array}$ & $\begin{array}{c}40.54 \pm 8.82 \mathrm{c} \\
(22-61)\end{array}$ & $\begin{array}{c}33.37 \pm 11 \mathrm{~d} \\
(19-62)\end{array}$ \\
\hline \multirow[t]{2}{*}{ Gender } & Male & 317 & $151 \mathrm{a}(79 \%)$ & 67 a $(70 \%)$ & 78 a $(81 \%)$ & $21 \mathrm{~b}(22 \%)$ \\
\hline & Female & 161 & 40 a $(21 \%)$ & 29 a $(30 \%)$ & 18 a $(19 \%)$ & $74 \mathrm{~b}(78 \%)$ \\
\hline \multirow[t]{2}{*}{ Smoker } & Yes & 123 & $74 a(39 \%)$ & $26 \mathrm{ab}(27 \%)$ & $20 \mathrm{~b}(21 \%)$ & $3 \mathrm{c}(3 \%)$ \\
\hline & No & 354 & $116 a(61 \%)$ & $70 \mathrm{ab}(73 \%)$ & $76 \mathrm{~b}(79 \%)$ & $92 \mathrm{c}(97 \%)$ \\
\hline \multirow[t]{2}{*}{ D.M. } & Yes & 73 & $43 \mathrm{a}(22.5 \%)$ & $22 \mathrm{a}(23 \%)$ & $8 \mathrm{~b}(8 \%)$ & $0 \mathrm{c}(0 \%)$ \\
\hline & NO & 405 & $148 \mathrm{a}(77.5 \%)$ & $74 a(77 \%)$ & $88 \mathrm{~b}(92 \%)$ & $95 \mathrm{c}(100 \%)$ \\
\hline \multirow[t]{2}{*}{$\mathrm{HCV} \mathrm{Ab}$} & Present & 351 & $165 \mathrm{a}(86 \%)$ & $90 \mathrm{a}(94 \%)$ & $96 \mathrm{~b}(100 \%)$ & $0 \mathrm{c}$ \\
\hline & Absent & 125 & $24 \mathrm{a}(14 \%)$ & 6a $(6 \%)$ & ob $(0 \%)$ & $95 \mathrm{c}(100 \%)$ \\
\hline \multirow[t]{2}{*}{ HBs Ag } & Present & 0 & $0(0 \%)$ & $0(0 \%)$ & $0(0 \%)$ & $0(0 \%)$ \\
\hline & Absent & 478 & $191(100 \%)$ & $96(100 \%)$ & $96(100 \%)$ & $95(100 \%)$ \\
\hline \multirow[t]{2}{*}{ Ascites } & Yes & 155 & $80 \mathrm{a}(42 \%)$ & $75 \mathrm{~b}(78 \%)$ & $0 \mathrm{c}(0 \%)$ & $0 \mathrm{c}(0 \%)$ \\
\hline & No & 314 & $102 \mathrm{a}(58 \%)$ & $21 \mathrm{~b}(22 \%)$ & $96 \mathrm{c}(100 \%)$ & $95 \mathrm{c}(100 \%)$ \\
\hline \multirow[t]{3}{*}{ Child score } & A & 81 & $69(36 \%)$ & $12(12.5 \%)$ & 0 & 0 \\
\hline & B & 96 & $69(36 \%)$ & $27(28 \%)$ & & \\
\hline & $\mathrm{C}$ & 106 & $49(28 \%)$ & $57(59.5 \%)$ & & \\
\hline \multirow[t]{3}{*}{ ALT: } & mean & & $64.79 \pm 52.737$ & $63.6 \pm 42.54$ & $63.41 \pm 44.22$ & $21.84 \pm 5.04$ \\
\hline & (Range) & & $(5-395)$ & $(6-290)$ & $(10-223)$ & (11-33) \\
\hline & Median & & $51 \mathrm{a}$ & $60 a$ & $54 a$ & $22 b$ \\
\hline \multirow[t]{3}{*}{ AST: } & mean & & $94.39 \pm 105.61$ & $53.91 \pm 31.72$ & $47.53 \pm 29.04$ & $26.68 \pm 5.07$ \\
\hline & (Range) & & $(16-1155)$ & $(16-176)$ & $(8-167)$ & $(15-37)$ \\
\hline & median & & $77 a$ & $46.5 b$ & $39.5 b$ & $27 \mathrm{c}$ \\
\hline \multirow[t]{3}{*}{ T-Bilirubin: } & mean & & $2.4 \pm 2.63$ & $3.25 \pm 2.51$ & $0.88 \pm 0.49$ & $0.79 \pm 0.16$ \\
\hline & (range) & & $(0.3-25.8)$ & $(0.2-19.7)$ & $(0.3-5)$ & $(0.5-1.1)$ \\
\hline & Median & & $1.7^{\mathrm{a}}$ & $2.86^{\mathrm{b}}$ & $0.84^{\mathrm{c}}$ & $0.8 \mathrm{c}$ \\
\hline \multirow[t]{3}{*}{ Albumin: } & mean & & $3.02 \pm 0.63$ & $2.55 \pm 0.51$ & $4.28 \pm 0.4$ & $4.45 \pm 0.34$ \\
\hline & (Range) & & $(1.8-4.8)$ & $(1.7-4.3)$ & $(3.2-5.4)$ & $(3.8-5.2)$ \\
\hline & Median & & $3.1^{\mathrm{a}}$ & $2.5^{\mathrm{b}}$ & $4.2^{\mathrm{c}}$ & $4.5 \mathrm{~d}$ \\
\hline \multirow[t]{3}{*}{$\alpha \mathrm{FP}:$} & mean & & $3933.25 \pm 16142$ & $35.21 \pm 40.1$ & $18.19 \pm 29.62$ & 0 \\
\hline & (Range) & & $(1.5-114170)$ & $(1.7-190)$ & $(0.65-112)$ & $0 \mathrm{~d}$ \\
\hline & Median & & $152^{\mathrm{a}}$ & $17.95^{\mathrm{b}}$ & $4.6^{c}$ & \\
\hline
\end{tabular}



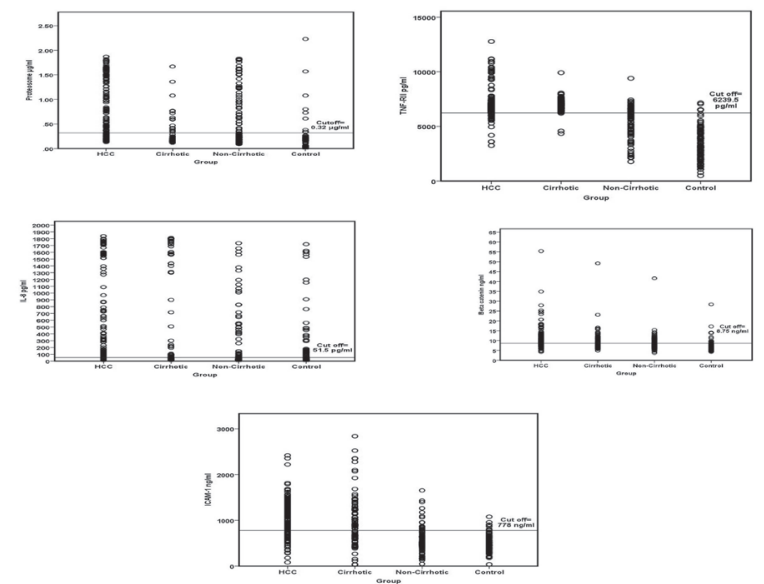

Figure 2. Scatter Plot of the Studied Markers in Different Investigated Groups Showing the Cutoff

Values. Sample groups on $\mathrm{x}$ axis and protein concentrations on $\mathrm{Y}$ axis (A) Proteosome (B) TNFR-II (C) IL-8 (D) $\beta$-catenin (E) ICAM-1
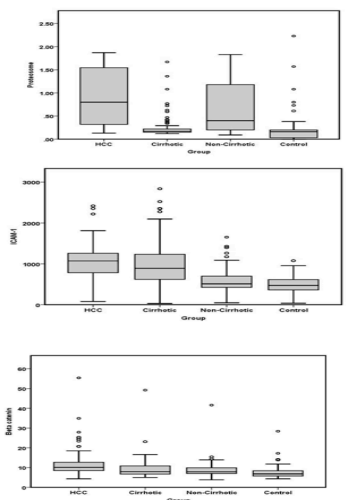

Figure 3. Box Plots Showing Distribution of Measured Serum Markers Levels with Median, Minimum and Maximum values in Different Investigated Groups and the Box Defines the Boundaries of the First and third Quartiles of Data. Sample groups on $x$ axis and protein concentrations on Y axis (A) Proteosome (B) IL-8 (C) ICAM-1 (D) TNFR-II (E) $\beta$-catenin assessed using the child score where $36 \%$ of HCC group were child A, $36 \%$ were child $\mathrm{B}$ and $28 \%$ were child $\mathrm{C}$ compared to $12.5 \%, 28 \%$ and $59.5 \%$ in cirrhotic group respectively (P-value $<0.001)$ matches the conclusion that $\mathrm{LC}$ group was in more decompensated pattern than HCC group.

The levels of studied biomarkers in the different groups were expressed as scatter plot showing cut-off in Figure (2), as box plot showing biomarkers distribution in Figure (3) and as mean $\pm \mathrm{SD}$, median and range Table (2). The median concentration of Proteasome was significantly higher in HCC than LC, CHC and control groups $(\mathrm{P}$-value $<0.001)$ with mean values $0.91 \pm 0.6$, $0.25 \pm 0.248,0.68 \pm 0.58$ and $0.19 \pm 0.31$ respectively. It was also significantly higher in $\mathrm{CHC}$ group than cirrhotic and control groups (P-value $<0.001$ ). Also the median concentration of serum IL-8 was significantly elevated in the LC and HCC groups compared to $\mathrm{CHC}$ and control groups with mean values $520.14 \pm 657.42,552.9 \pm 732.2$, $283.8 \pm 442.69$ and $238.8 \pm 431.6 \mathrm{pg} / \mathrm{ml}$ respectively (P-value $<0.001$ ). However, no significant difference was noticed in patients with HCC and LC (P-value $=0.09$ ). On the other hand,the median concentration SICAM-1 significantly elevated in HCC group compared to LC, CHC and control groups with mean values $1034.68 \pm 373.72$, $978.17 \pm 540.17,569.99 \pm 286.99$ and $493 \pm 188.06 \mathrm{ng} /$ $\mathrm{ml}$ respectively (P-value $<0.001)$. However, there was no significant difference between $\mathrm{CHC}$ and control groups $(\mathrm{P}$-value $=0.07)$. On the other hand the median concentration sICAM-1 significantly elevated in HCC group compared to LC, $\mathrm{CHC}$ and control groups with mean values $1034.68 \pm 373.72,978.17 \pm 540.17,569.99 \pm 286.99$ and $493 \pm 188.06 \mathrm{ng} / \mathrm{ml}$ respectively (P-value $<0.001$ ). However, there was no significant difference between $\mathrm{CHC}$ and control groups ( $\mathrm{P}$-value $=0.07)$. Also the median concentration of sTNFR-II was significantly elevated in patients with LC compared to HCC, CHC and control groups (P-value $<0.001)$, also it was significantly

Table 2. Levels of Studied Serological Markers in Different Studied Groups

\begin{tabular}{|c|c|c|c|c|c|}
\hline & $\mathrm{HCC} n=192$ & Cirrhotic $n=96$ & Non-Cirrhotic $n=95$ & Control $n=95$ & $P$ value \\
\hline \multicolumn{6}{|l|}{ Proteosome } \\
\hline Median & $0.8 \mathrm{a}$ & $0.17 \mathrm{~b}$ & $0.4 \mathrm{c}$ & $0.16 \mathrm{~d}$ & \multirow[t]{3}{*}{$<0.001$} \\
\hline Mean \pm SD & $0.91 \pm 0.6$ & $0.25 \pm 0.25$ & $0.68 \pm 0.58$ & $0.18 \pm 0.3$ & \\
\hline Range & $0.13-1.87$ & $0.12-1.67$ & $0.09-1.83$ & $0.01-2.22$ & \\
\hline \multicolumn{6}{|l|}{ IL-8 } \\
\hline Median & $107 \mathrm{a}$ & $55 \mathrm{a}$ & $36.5 \mathrm{~b}$ & $47 b$ & \multirow[t]{3}{*}{$<0.001$} \\
\hline Mean \pm SD & $518.19 \pm 656.23$ & $552.9 \pm 732.2$ & $283.76 \pm 442.7$ & $238.8 \pm 431.6$ & \\
\hline Range & 14-1837 & 14-1811 & 8-1734 & 3-1719 & \\
\hline \multicolumn{6}{|l|}{ ICAM-1 } \\
\hline Median & $1072.5 \mathrm{a}$ & $892 b$ & $510.5 c$ & $473 c$ & \multirow[t]{3}{*}{$<0.001$} \\
\hline Mean \pm SD & $1034.73 \pm 372.7$ & $978.17 \pm 540.17$ & $570 \pm 287$ & $493 \pm 188$ & \\
\hline Range & 79-2419 & $31-2838$ & $46-1654$ & $37-1078$ & \\
\hline \multicolumn{6}{|l|}{ TNFR-II } \\
\hline Median & $6785 a$ & $7011.5 b$ & $5948.5 c$ & $3190.5 \mathrm{~d}$ & \multirow{3}{*}{$<0.001$} \\
\hline Mean \pm SD & $7058.31 \pm 1338.78$ & $6984.5 \pm 626.8$ & $5456 \pm 1531.7$ & $3400 \pm 1519$ & \\
\hline Range & 3250-12776 & 4351-9919 & $1772-9403$ & $495-7157$ & \\
\hline \multicolumn{6}{|l|}{ Beta catenin } \\
\hline Median & $10.1 \mathrm{a}$ & $7.95 \mathrm{~b}$ & $7.85 \mathrm{~b}$ & $6.8 \mathrm{c}$ & \multirow[t]{3}{*}{$<0.001$} \\
\hline Mean \pm SD & $11.26 \pm 5.49$ & $9.34 \pm 5.13$ & $8.81 \pm 4.07$ & $7.5 \pm 3.2$ & \\
\hline Range & $4.3-55.4$ & 5- 49.2 & $3.8-41.6$ & $4.3-28.4$ & \\
\hline
\end{tabular}

*Groups bearing different initials are significantly different 
Serum Biomarkers for Early Detection of Hepatocellular Carcinoma Associated with HCV Infection in Egyptian Patients Table 3. ROC Analysis Showing Cut-off, Sensitivity, Specificity, AUC, PPV and NPV of the Studied Markers

\begin{tabular}{lrrrrr}
\hline & Proteosome & IL-8 & ICAM-1 & TNFR-II & $\beta$-catenin \\
\hline Sensitivity & $75.9 \%$ & $70.4 \%$ & $75.8 \%$ & $86.3 \%$ & $70.7 \%$ \\
Specificity & $73.4 \%$ & $52.3 \%$ & $71.8 \%$ & $51.8 \%$ & $68.6 \%$ \\
AUC & 0.803 & 0.631 & 0.776 & 0.722 & 0.729 \\
Accuracy & $75.47 \%$ & $59.74 \%$ & $73.17 \%$ & $66.95 \%$ & $69.25 \%$ \\
PPV & $67.13 \%$ & $49.81 \%$ & $63.72 \%$ & $55.74 \%$ & $59.73 \%$ \\
NPV & $82.38 \%$ & $72.68 \%$ & $81.67 \%$ & $85.8 \%$ & $77.78 \%$ \\
Cut-off & $0.32 \mu \mathrm{g} / \mathrm{ml}$ & $51.5 \mathrm{pg} / \mathrm{ml}$ & $778 \mathrm{ng} / \mathrm{ml}$ & $6239.5 \mathrm{pg} / \mathrm{ml}$ & $8.75 \mathrm{ng} / \mathrm{ml}$ \\
\hline
\end{tabular}

higher in $\mathrm{HCC}$ compared to $\mathrm{CHC}$ and control groups (P-value<0.001) and with mean values 7059.35 \pm 1342.24 , $6984.5 \pm 626.8,5456 \pm 1531.66$ and $3400 \pm 1519 \mathrm{pg} / \mathrm{ml}$ respectively. Median concentration of $\beta$-catenin was significantly elevated in HCC group compared to the other groups (P-value $<0.001$ ) with mean values 11.28 \pm 5.49 , $9.34 \pm 5.13,8.8 \pm 4.07$ and $7.5 \pm 3.2 \mathrm{ng} / \mathrm{ml}$ respectively, whereas there was not any significant differences in its levels among $\mathrm{LC}$ and $\mathrm{CHC}$ groups $(\mathrm{P}=0.76)$.

Further analysis of the data using Receiving Operating Characteristic (ROC) analysis curves and the corresponding area under the curve were attempted for the studied markers to investigate their diagnostic accuracy between HCC and other groups demonstrating cut off values with their specificity ,sensitivity, PPV(positive predictive values) and NPV( negative predictive values) as shown in Table (3) \& Figure (1). It has been revealed that serum level of Proteasome had a sensitivity of $75.9 \%$ and specificity of $73.4 \%$ at cut off value of $0.32 \mu \mathrm{g} / \mathrm{ml}$, PPV was $67.13 \%$ and NPV was $82.38 \%$ with AUC 0.803 and the overall accuracy was $75.47 \%$. Serum level of IL-8 had sensitivity of $70.4 \%$ and specificity of $52.3 \%$ at cut off value of $51.5 \mathrm{pg} / \mathrm{ml}$, PPV was $49.81 \%$ and NPV was $72.68 \%$ with AUC 0.633 and the overall accuracy was $59.74 \%$. While serum level of sICAM-1 had a sensitivity of $75.8 \%$ and the specificity of 71.8 at cut off value of 778 $\mathrm{ng} / \mathrm{ml}$, PPV was $63.72 \%$, NPV was $81.67 \%$ with AUC 0.766 and the overall accuracy was $73.17 \%$. Serum level of sTNFR-II showed a sensitivity of $86.3 \%$ and specificity of $51.8 \%$ at cut off value of $6239.5 \mathrm{pg} / \mathrm{ml}$, PPV was $55.74 \%$, NPV was $85.8 \%$ with AUC 0.722 and the overall accuracy was $66.95 \%$. Serum level of $\beta$-catenin had a sensitivity and specificity of $70 \%$ and $68.6 \%$ respectively at cut off value of $8.75 \mathrm{ng} / \mathrm{ml}$, PPV was $59.73 \%$, NPV was $77.78 \%$ with AUC 0.729 and the overall accuracy was $69.25 \%$.

\section{Discussion}

Hepatocellular carcinoma (HCC) is a common problem worldwide which ranks the 5 th and 7 th most common cancer among men and women respectively (Goe et al., 2014). In Egypt, hepatocellular carcinoma (HCC) ranks as the second most common cancer in men and the 6th most common cancer in women (GLOBACAN, 2008). This rising incidence of HCC may be due to high prevalence of hepatitis $\mathrm{C}$ virus ( $\mathrm{HCV}$ ), estimated among the general population to be around $14 \%$ (El-Zanaty et al., 2009). The prognosis of HCC is very difficult which necessitates finding of new appropriate either single or panel serum markers that could be used for early detection of HCC in high risk patients. As the level of serum alpha- fetoprotein $(\alpha \mathrm{FP})$, recommended marker, frequently was not elevated at a significant proportion in patients with early-stage, potentially curable, HCC (Zhou et al., 2013).

Our aim of this study is to evaluate serum Intercellular Adhesion Molecules (sICAM-1), Beta catenin ( $\beta$-catenin), Interleukin 8 (IL-8), Proteasome and soluble Tumor Necrosis Factor Receptor II (sTNFR-II) in early detection of HCC.

The current study showed that serum level of $\alpha \mathrm{FP}$ was significantly elevated in patients with HCC than other groups, a finding that came in agreement with previous studies of many authors (Gad et al., 2005; Mittal et al., 2011; Guan et al., 2012).

The serum level of sICAM-1 was significantly elevated in HCC group compared to $\mathrm{LC}, \mathrm{CHC}$ and control groups (P-value $<0.001)$. However, there was no significant difference between $\mathrm{CHC}$ and control groups (P-value $=0.07)$. This data comes in agreement with previous reports by (Shimizu et al., 1995; Moriyama et al., 2006 and Mohamed et al., 2014), who reported that increasing level of sICAM-1 over time are significant risk factors for the occurrence of $\mathrm{HCC}$ in patients with $\mathrm{HCV}$-associated $\mathrm{CH}$ or liver cirrhosis (LC). The same conclusion was detected at gene level by (Rizk et al., 2012). Against to our results, the study results by (Hyodo et al., 1993 ) who reported that there was no difference in serum levels of sICAM-1 between their patients with HCC and liver cirrhosis. This is may be due to difference in the sensitivity of ELISA kit and small population size. The elevated serum level of sICAM-1 in HCC group is due to the tumor antigens stimulate the expression of ICAM-1 by immune cells in addition to the expression of ICAM-1 by tumor cells themselves (Bernier et al., 2011). Serum level of sICAM-1 showed a sensitivity of $75.8 \%$ and a specificity of $71.8 \%$ at a cut off level $778 \mathrm{ng} / \mathrm{ml}$ with AUC 0.776 between HCC and other groups. Thus, regular measurements of sICAM-1 concentrations would be of clinical significance and could be used as a prognostic marker for early detection of HCC with fair diagnostic accuracy as AUC was in the range of (0.7-0.79).

Serum level of $\beta$-catenin was significantly elevated in HCC group compared to the other groups (P-value $<0.001)$, whereas there was not any significant difference in its level among LC and CHC groups (P-value= 0.76). This result comes in agreement with previous studies by (Zekri et al., 2011), where higher serum level of $\beta$-catenin was measured in patients with HCC compared with those in $\mathrm{CH}$, ASC (chronic HCV with persistent normal alanine aminotransferase levels ) and healthy controls patients. In concordance with our results, previous work by (Li et al., 2014; Guan et al., 2012) who reported higher nuclear 
accumulation of $\beta$-catenin by immunohistochemistery in HCC tissue than in the corresponding para-carcinoma, cirrhotic and normal tissues. The elevated level and stability of the $\beta$-catenin and in HCC group is due to point mutation in its amino terminus that changes the serine and threonine residues, thereby blocking its phosphorylation and subsequent degradation (Morin et al., 1997; Rubinfeld et al., 1997). Also, other studies revealed that mutation in Axin-1 gene, an important regulator of $\beta$-catenin, leads to the stability of the $\beta$-catenin and subsequent its nuclear accumulation (Satoh et al., 2000). Hence, Wnt/ $\beta$-catenin pathway is activated that is involved in many vital processes including cell proliferation (Clevers, 2006). Serum level of $\beta$-catenin had a sensitivity and specificity of $70 \%$ and $68.6 \%$ respectively at cut off value of $8.75 \mathrm{ng} /$ $\mathrm{ml}$ with AUC 0.729 between HCC and LC groups. This data suggested that serum level of $\beta$-catenin could be used as prognostic marker for early detection of $\mathrm{HCC}$ with fair diagnostic accuracy as AUC was in the range of (0.7-0.79).

Serum level of Proteasome was significantly higher in HCC than LC, CHC and control groups (P-value $<0.001$ ). This result comes in agreement with previous studies by (Henry et al., 2009) where plasma Proteasome level was significantly higher in patients with HCC compared to controls and LC patients. However, serum level of Proteasome was also significantly higher in $\mathrm{CHC}$ group than cirrhotic and control groups (P-value $<0.001)$. The possible role of Proteasome in hepatocellular carcinoma was revealed from study by (Higashitsuji et al., 2005) who reported the over expression of the gankyrin protein by gene expression analysis. This protein was identified as component of the 19S Proteasomal regulatory particle and it can associate with protein Mdm2 (E3 ligase of p53) and promote its interaction with p53 (tumor suppressor gene) and subsequent degradation. P53 is implicated in a wide range of cell processes including apoptosis induction, stimulation of DNA reparation, cell cycle arrest, and regulation of basic metabolism; so its degradation leads to increasing cell proliferation and subsequently tumor formation (Chumakov, 2007). Also, the potential role of Proteasome in hepatocellular carcinoma was revealed from previous study by (Albekairy et al., 2013) who reported that application of Proteasome inhibitors represent a noval potential therapy in liver cancer. Serum level of Proteasome had a sensitivity of $75.9 \%$ and specificity of $73.4 \%$ at cut off value of $0.32 \mu \mathrm{g} / \mathrm{ml}$ with AUC 0.803 between HCC and other groups. This data suggested that serum level of Proteasome is a reliable marker for early detection of HCC with good diagnostic accuracy as AUC was in the range of $(0.8-0.89)$.

The level of serum IL- 8 was significantly elevated in the $\mathrm{HCC}$ and $\mathrm{LC}$ groups compared to $\mathrm{CHC}$ and control groups ( $\mathrm{P}$-value $<0.001)$. This result comes in agreement with previous study by (Ren et al., 2003) as the level of serum IL-8 was significantly elevated in the HCC group compared to control group. Also, this result comes in concordance with previous study by (Zimmermann et al., 2011) as the level of serum IL-8 was significantly elevated in the LC group compared to $\mathrm{CH}$ and control groups. However, no significant difference was noticed between HCC and LC groups, also between CHC and control group $(\mathrm{P}$-value $=0.09)$ in the current study. The high serum level of IL-8 in HCC group is due to its secretion by tumor cells. The high serum level of IL- 8 in LC group is due significantly increased numbers of macrophages with progression of liver fibrosis lcirrhosis which also the main important target of IL-8 in liver cirrhosis (Zimmermann et al., 2011). Serum level of IL-8 had a sensitivity of $70.4 \%$ and specificity of $52.3 \%$ at cut off value of $51.5 \mathrm{pg} / \mathrm{ml}$ with AUC 0.631 between HCC and other groups. This result suggested that diagnostic accuracy of IL-8 in the early detection of $\mathrm{HCC}$ was poor as $\mathrm{AUC}$ was in the range (0.60-0.69).

Serum level of sTNFR-II was significantly elevated in patients with $\mathrm{HCC}$ compared to $\mathrm{CHC}$ and control groups (P-value $<0.001)$. This result comes in agreement with previous work by (Zekri et al., 2010), where serum level of sTNFR-II was significantly elevated in patients with HCC compared to CLD (chronic liver disease associated with elevated liver enzyme levels), ASC and control groups. However, the serum level of sTNF-RII was significantly elevated in patients with LC compared to HCC in the currennt study (P-value $<0.001)$. The possible role of TNF- $\alpha$ receptor 2 signaling pathway was the activation of two important transcription factors NF- $\varkappa \mathrm{B}$ or AP-1 (Molenates et al., 2013). NF- $x$ B pathway play a vital role in tumorgensis as it controlled many vital process e.g productions of cell regulator and anti-apoptotic proteins resulting in stimulation of cell proliferation and inhibition of apoptosis. Also, NF-kB pathway play a vital role in inflammation, largely based on the role of NF-kB in the expression of pro inflammatory genes including cytokines, chemokines, and adhesion molecules (Lawrence, 2009). Serum level of sTNFR-II showed a sensitivity of $86.3 \%$ and specificity of $51.8 \%$ at cut off value of $6239.5 \mathrm{pg} / \mathrm{ml}$ with AUC 0.722 between HCC and other groups. This result suggested that sTNFR-II could be used as prognostic marker for early detection of HCC with fair diagnostic accuracy as AUC was in the range of (0.7-0.79).

In conclusion, These findings support the potential role of Proteasome, sICAM-1, sTNFR-II and $\beta$-catenin in early detection of HCC and discrimination of malignant cases from the other studied non-malignant cases. Also, using this panel of serological markers in combination of $\alpha$ FP may offer improved diagnostic performance over $\alpha \mathrm{FP}$ alone in the early detection of HCC. .

\section{References}

Aberle H, Schwartz H and Kemler H (1996). Cadherin-catenin complex: protein interactions and their implications for cadherin function. J Cell Biochem, 61, 514-523.

Adler KB, Fischer BM, Wright D T, et al (1994).Interactions between respiratory epithelial cells and cytokines: Relationships to lung inflammation. Ann NY Acad Sci, 725, 128-45.

Albekairy A, Alkatheri A, and Mansour M (2013). Inhibition of ubiquitin-proteasome pathway: A possible treatment of hepatocellular carcinoma. IJMMS, 5, 312-19.

Bernier AJ, Zhang J, Lillehoj E, et al (2011). Non-cysteine linked MUC1 cytoplasmic dimmers are required for Src recruitment and ICAM-1 binding induced cell invasion. Mol Cancer, 10, 93. 
Serum Biomarkers for Early Detection of Hepatocellular Carcinoma Associated with HCV Infection in Egyptian Patients

Bradley JR (2008). TNF-mediated inflammatory disease. $J$ Pathol, 214, 149-60.

Chumakov PM (2007). Versatile functions of p53 protein in multicellular organisms. Biochemistry, 72, 1399-421.

Clevers H (2006). Wnt/ $\beta$-catenin signaling in development and disease. Cell, 127, 469-80.

Diez-Ruiz A, Tilz GP,Zangerle R, et al (1995). Soluble receptors for tumour necrosis factor in clinical laboratory diagnosis. Eur J Haematol, 54, 1-8.

El-Zanaty F, Way A (2008). Egypt Demographic and Health Survey (Egyptian Ministry of Health, El-Zanaty and Associates and Macro International, 2009).

Gad A, Tanka E, Matsumoto A, et al (2005). Ethnicity affects the diagnostic validity of alpha-fetoprotein in hepatocellular carcinoma. Asia Pac J Clin Oncol, 1, 64-70.

Gao J, Xie L, Yang W, et al (2012). Risk factors of hepatocellular carcinoma - current status and perspectives. Asian Pac J Cancer Prev, 13, 743-52.

GLOBOCAN 2008 database (version 1.2). Available online: http://globocan.iarc.fr

Guan C-N, Chen X-M, Lou H-Q, et al (2012). Clinical significance of axin and $\beta$-catenin protein expression in primary hepatocellular carcinomas. Asian Pac J Cancer Prev, 13, 677-81.

Henry L, Lavabre-Bertrand T, Vercambre L, et al (2009). Plasma proteasome level is a reliable early marker of malignant transformation of liver cirrhosis. Gut, 58, 833-8.

Higashitsuji H, Itoh K, Sakurai T, et al (2005). The oncoprotein gankyrin binds to MDM2/HDM2, enhancing ubiquitylation and degradation of p53. Cancer Cell, 8, 75-87.

Hiotis SP, Rahbari NN, Villanueva GA, et al (2012). Hepatitis $B$ vs. hepatitis $C$ infection on viral hepatitis-associated hepatocellular carcinoma. BMC Gastroenterol, , 64.

Hyodo I, Jinno K, Tanimizu M, et al (1993). Detection of circulating intercellular adhesion molecule- 1 in hepatocellular carcinoma. Int J Cancer, 55, 775-9.

Kanayama H, Tanaka K, Aki M, et al (1991).Changes in expressions of proteasome and ubiquitin genes inhuman renal cancer cells. Cancer Res, 51, 6677-85.

Kumatori A, Tanaka K, Inamura N, et al (1990). Abnormally high expression of proteasomes in human leukemic cells. Proc Natl Acad Sci USA, 87, 7071-5.

Laurent-Puig P, Zucman-Rossi J (2006). Genetics of hepatocellular tumors. Oncogene, 25, 3778-86.

Lawrence, T. (2009). The nuclear factor NF-kappaB pathway in inflammation. Cold Spring Harbor Perspectives in Biology, 1, 1651 .

Lawson C, Wolf S (2009). ICAM-1 signaling in endothelial cells. Pharmacol Rep, 61, 22-32.

Li P, Cao Y, Li Y, et al (2014). Expression of Wnt-5a and $\beta$-catenin in primary hepatocellular carcinoma. Int J Clin Exp Pathol, 7, 3190-5.

McConnell BB and Yang VW (2009). The role of inflammation in the pathogenesis of colorectal cancer. Curr Colorectal Cancer Rep, 5, 69-74.

Mittal A, Sathian B, Chandrashekharan N, et al (2008). Diagnostic significance of alpha fetoprotein in carcinomas of liver and biliary tract - a comparative study from western region of nepal. Asian Pac J Cancer Prev, 12, 3475-8.

Moelants E, Mortier A, Van Damme J, et al (2013). Regulation of TNF- $\alpha$ with a focus on rheumatoid arthritis. Immunol Cell Biol, 91, 393-401.

Mohamed AA, Saad A, Saad S, et al (2014). Role of Intercellular adhesion molecules as tumor marker for detection of Hepatocellular carcinoma. IJAR, 2, 705-13.

Morin PJ, Sparks AB, Korinek V, et al (1997). Activation of $\beta$-catenin-Tcf signaling in colon cancer by mutation in $\beta$-catenin or APC. Science, 275, 1787-90.

Moriyama M, Matsumura H, Shioda J, et al (2006). Measurement of human intercellular adhesion molecule 1 in the blood is useful for predicting the occurrence of hepatocellular carcinomas from chronic hepatitis $\mathrm{C}$ and liver cirrhosis. Intervirology, 49, 327-38.

Ren Y, Poon RT, Tsui H, et al (2003). Interleukin-8 Serum Levels in patients with hepatocellular carcinoma : correlations with clinicopathological features and prognosis interleukin-8 serum levels in patients with hepatocellular carcinoma : correlations with clinicopathological features and prognosis. Clin Cancer Res, 9, 5996-6001.

Rizk NM and Derbala MF (2012). Genetic polymorphisms of ICAM 1 and IL28 as predictors of liver fibrosis severity and viral clearance in hepatitis C genotype 4. Clin Res Hepatol Gastroenterol, 5, 259-8.

Rothe J, Gehr G, Loetscher H, et al (1992).Tumor necrosis factor receptors-structure and function. Immunol Res, 11, 81-90.

Satoh S, Daigo Y, Furukawa Y, et al (2000). AXIN1 mutation in hepatocellular carcinomas and growth supression in cancer cells by virus-mediated transfer of AXIN1. Nat Genet, 24, 245-50.

Shimizu Y, Minemura M, Tsukishiro T, et al (1995). Serum concentration of intercellular adhesion molecule-1 in patients with hepatocellular carcinoma is a marker of the disease progression and prognosis. Hepatology, 22, 525-531.

Sorokin AV, Kim ER and Ovchinnikov LP (2009). Proteasome system of protein degradation and processing. Biochemistry, 74, 1411-42.

Waugh DJ and Wilson C (2008).The Interleukin-8 Pathway in Cancer. Clin Cancer Res, 14, 6735-41 .

Yamashita T, Honda M and Kaneko S (2011). Molecular mechanisms of hepatocarcinogenesis in chronic hepatitis $\mathrm{C}$ virus infection. J Gastroenterol Hepatol, 26, 960-4.

A-R N, El-Din H M, BahnassyAA, et al (2010). Serum levels of soluble Fas, soluble tumor necrosis factor-receptor II, interleukin- 2 receptor and interleukin- 8 as early predictors of hepatocellular carcinoma in Egyptian patients with hepatitis C virus genotype-4. Comp Hepatol, $9,1$.

Zekri A-RN, Bahnassy AA, Alam El-Din HM, et al (2011). Serum levels of $\beta$-catenin as a potential marker for genotype 4/hepatitis C-associated hepatocellular carcinoma. Oncol Rep, 26, 825-31.

Zekri AR, Bahnassy AA, Abdel-Wahab SA, et al (2009). Expression of pro- and anti-inflammatory cytokines in relation to apoptotic genes in Egyptian liver disease patients associated with HCV-genotype-4.J Gastroenterol Hepatol, 24, 416-28.

Zhao YJ, Ju Q and Li GC (2013): Tumor markers for hepatocellular carcinoma. Mol Clin Oncol, 1, 593-8.

Zimmermann HW, Seidler S, Gassler N, et al (2011). Interleukin-8 is activated in patients with chronic liver diseases and associated with hepatic macrophage accumulation in human liver fibrosis. PloS One, 6, 21381 